\title{
Coleções particulares incorporadas à Coleção Helmintológica do Instituto Oswaldo Cruz (CHIOC). I: Coleção do Instituto Pasteur de São Paulo
}

\author{
Dely Noronha 1, 2, Roberta de Bragança ${ }^{1}$, Joaquim Júlio Vicente 1, Luís C. Muniz Pereira 1,3 \\ ${ }^{1}$ Laboratório Helmintos Parasitos de Vertebrados, Departamento de Helmintologia, Instituto Oswaldo Cruz. Avenida Brasil \\ 4365, 21045-900 Rio de Janeiro, Rio de Janeiro, Brasil. \\ 2 Curadora da CHIOC. Autora correspondente. E-mail: dnoronha@ioc. fiocruz.br \\ ${ }^{3}$ Curador substituto da CHIOC. E-mail: Imuniz@ioc.fiocruz.br
}

\begin{abstract}
Private collections incorporated to the Helminthological Collection of the Oswaldo Cruz Institute (CHIOC). I: Collection of the Pasteur Institute of São Paulo. This paper deals with data on the historical background of the first private helminth survey incorporated to an institutional helminthological collection in Brazil. The samples are represented by nematodes, digenetic trematodes and acanthocephalans recovered from vertebrate hosts, that are included in a check list.

KEY WORDS. Brazil, helminths, history, survey.
\end{abstract}

\begin{abstract}
RESUMO. O presente trabalho fornece dados históricos básicos sobre o primeiro acervo particular de helmintos a ser incorporado a uma coleção helmintológica institucional brasileira. As amostras são representadas por nematóides, trematódeos digenéticos e acantocéfalos parasitos de hospedeiros vertebrados e que são agora catalogados.

PALAVRAS CHAVES. Brasil, helmintos, história, levantamento.
\end{abstract}

\begin{abstract}
O presente trabalho faz considerações sobre a primeira das incorporações de coleções particulares à Coleção Helmintológica do Instituto Oswaldo Cruz (CHIOC) e que, de certa forma, representam a gênese desta coleção, a maior da América do Sul e uma das maiores do mundo.

O objetivo deste estudo, além de fornecer um levantamento taxonômico da incorporação da coleção proveniente do Instituto Pasteur de São Paulo, é, também, o de contextualizar historicamente a formação da CHIOC dentro do âmbito da ciência nacional do início do século XX.
\end{abstract}

\section{MATERIAL E MÉTODOS}

Durante as etapas iniciais para o desenvolvimento de um banco de dados proposto por Noronha et al. (2003) para a informatização da CHIOC, foi verificada a existência de treze amostras, pertencentes originalmente ao Instituto Pasterur de São Paulo, coletadas entre 1912 e 1915 por Antonio Carini e Jesuíno Maciel.

As amostras foram revistas e seus representantes, tanto os helmintos quanto os hospedeiros, tiveram sua posição sis- temática atualizada, com base em AMIN (1985), Travassos et al. (1969) e VicenTe et al. $(1993,1995,1997)$.

\section{RESULTADOS}

O acervo original da coleção do Instituto Pasteur de São Paulo, e que foi incorporado, apesar do pequeno número, é de importância helmintológica, desde que, entre as amostras, existem duas espécies tipo, uma representando o nematóide, Macielia macieli (Travassos, 1915) Travassos, 1935 e outra, um acantocéfalo, Oligacanthorhynchus carinii (Travasos, 1915) Schmidt, 1972.

As necropsias efetuadas por Carini e Maciel totalizam $76,4 \%$ e as realizadas separadamente por cada pesquisador resultaram em $11,76 \%$.

As amostras são constituídas, principalmente, pelos Nematoda representando $62,5 \%$ das amostras, seguidos pelos Digenea com 25\%, e os Acanthocephala com 12,5\%. Com relação aos hospedeiros, os mamíferos aparecem com 69,23\% das necropsias, seguidos pelas aves com $33,33 \%$ e répteis com $11,11 \%$. Quanto às proveniências, somente o Instituto Pasteur de São Paulo é referido como sendo o da origem das necropsias. 


\section{Nematoda}

Ancylostomatidae Looss, 1905, espécie: Ancylostoma caninum (Ercolani, 1859), Hall,1913, hospedeiros: Canis familiaris Linnaeus, 1758, Cerdocyon thous Linnaeus, 1758, sítios de infecção: estômago, intestino, intestino delgado, CHIOC: 1182, 1738, 2281.

Comentário. A amostra 1.182 foi obtida de intestino de $\mathrm{Ca}$ nis familiaris, a amostra 1.738 de estômago de Cerdocyon thous e a 2.281 de intestino delgado de um felídeo não identificado.

Ascarididae Baird, 1853, espécie: Ascaridia columbae (Gmelin, 1789) Travassos, 1913, hospedeiro: Columba livia domestica (Gmelin, 1789); sítio de infecção: intestino delgado, CHIOC: 1647; espécie: Toxocara canis (Werner, 1782) Stiles, 1902, hospedeiro: Canis familiaris Linnaeus, 1758, sítio de infecção: intestino, CHIOC: 11767.

Comentário. Incluída inicialmente como Belascaris marginata Railliet \& Henry, 1911.

Toxocara mystax (Zeder, 1800) Stiles, 1907, hospedeiro: Felis catus domesticus Linnaeus, 1758, sítio de infecção: estômago, CHIOC: 1772.

Aspidoderidae Freitas, 1956, espécie: Aspidodera raillieti Travassos, 1913, hospedeiro: Didelphis aurita Wied-Neuwied, 1826, sítio de infecção: intestino, CHIOC: 1154.

Kathalaniidae Travassos, 1918, espécie: Cruzia tentaculata (Rudolphi, 1819) Travassos, 1917, hospedeiro: Didelphis aurita Wied-Neuwied, 1826, sítio de infecção: intestino, CHIOC: 1153

Molineidae Durette-Desset \& Chabaud, 1977, espécie: Macielia macieli (Travassos, 1915) Travassos, 1935, hospedeiro: Dasypus novemcinctus Linnaeus, 1758 ( = Tatus novemcinctus) sítio de infecção: estômago, CHIOC: 500 a-c (tipos), 1.471 (cótipos).

Comentário. O helminto foi inicialmente incluído como Trichostrongylus macieli Travassos, 1915, e o hospedeiro como Tatus (T.) novemcinctus Linnaeus.

Oxyuridae Cobold, 1864, espécie: Trypanoxyurus (T.) minutus (Schneider, 1866) Inglis \& Dias-Ungria, 1959, hospedeiro: Alouatta fusca (Geoffroy, 1812), sítio de infecção: intestino, CHIOC: 572.

Comentário. Incluído inicialmente como Oxyurus fusca Schenider, 1866.

Physalopteridae Leiper, 1908, espécie: Physaloptera retusa Rudophi, 1819, hospedeiro: Tupinambis teguixin Linnaeus, 1758, CHIOC: 1.745 .

Comentário. O hospedeiro foi inicialmente incluído como com Tejus teguixin (Linnaeus).

\section{Digenea}

Brachylaemidae, espécie: Brachylaima opisthothrias (Lutz, 1895) Dollfus, 1935, hospedeiro: Didelphis aurita Wied-Neuwied, 1826, sítio de infecção: intestino delgado, CHIOC: 1845,1846 .

Revista Brasileira de Zoologia 21 (2): 303-305, junho 2004
Comentário. Espécie incluída como Harmostomum opistorchis Lutz, 1895.

\section{Archiacanthocephala}

Oligacanthorhynchidae, espécie: Oligacanthorhynchus carinii (Travassos, 1917) Schmidt, 1972, hospedeiro: Dasypus novemcinctus Linnaeus, 1758, sítio de infecção: intestino delgado, CHIOC: 484, 537 (cótipo).

Comentário. Helminto inicialmente incluído como Hammaniella carinii Travassos, 1917, obtido de Tatus (T.) novemcinctus (Linnaeus). Essa espécie de acantocéfalo, junto com Oligacanthorhynchus iheringi Travassos, 1917, Prosthenorchis avicola Travassos, 1917 e representantes dos gêneros Empodius Travassos, 1916, Macracanthorhynchus Travassos, 1916 e Oncicola Travassos, 1916 foram referidos pela primeira vez em 1917 durante um congresso científico. O resumo informava que os resultados seriam veiculados sob a forma de monografia a ser publicada, o que ocorreu ainda no mesmo ano, quando os acantocéfalos tiveram suas descrições ampliadas e figuras fornecidas (Travassos 1917).

\section{DISCUSSÃO}

A Coleção Helmintológica do Instituto Oswaldo Cruz tem sido objeto de trabalhos anteriores e neste sentido, a partir das pesquisas realizadas, se constitui como parte importante, a delimitação da história da formação das coleções científicas no Brasil. Portanto, estaremos inserindo a CHIOC dentro de seu contexto histórico-científico, fato este, que possibilitará uma maior compreensão da dimensão e importância desta coleção institucional.

Não havia, na época da implantação da CHIOC em 1909, nenhuma tradição de patrocínio particular à ciência que existia no Brasil, e sendo o valor a ela atribuído, pequeno demais para tornar tal patrocínio em um método exeqüível de encorajar o seu desenvolvimento, as únicas fontes prováveis de apoio à investigação científica no Brasil eram as governamentais, não se podendo dissociar a construção da ciência nacional do estado, por falta de autonomia administrativa e financeira (STEPAN 1976).

Apesar disso, a CHIOC é hoje, uma coleção reconhecida como centro de referência, nacional e internacional, para pesquisas na área da helmintologia e teve o seu inicio com o acervo das necropsias de José Gomes de Faria, médico, que trabalhou no antigo Instituto Soroterápico do Rio de Janeiro, atual Instituto Oswaldo Cruz e de seu discípulo Lauro Pereira Travassos, em 1909. No que diz respeito a esta data, é feita uma correção, pois Noronha et al. (2003), seguindo Lichtenfels \& Pritchard (1982), reportaram-se erroneamente, a 1907, ano em que as publicações de Gomes de Faria se referiam à vacina do carbúnculo e não a helmintos.

Além do depósito do material relativo às necropsias de pesquisadores já lotados no Instituto Oswaldo Cruz, houve também doações de material helmintológico de coleções par- 
ticulares e/ou institucionais do início do século XX. O material helmintológico do Instituto Pasteur de São Paulo, descrito por Travassos durante o período de 1915-1917, constitui-se na primeira incorporação particular à CHIOC.

O Instituto Pasteur de São Paulo, em sua origem (1903), era uma fundação não governamental, sem fins lucrativos, de reconhecida utilidade pública, não tendo qualquer ligação institucional com o Instituto Pasteur de Paris. Mesmo não sendo o único, o Instituto Pasteur de São Paulo se diferenciava dos demais, alocados no Brasil, por suas práticas e pelo seu compromisso efetivo no que se refere à contribuição no campo da bacteriologia, ensino e produção de vacinas, se constituindo como um dos principais centros de pesquisa biomédica paulista na segunda década do século XX. Em maio de 1906, Antonio Carini, torna-se diretor do Instituto Pasteur de São Paulo e, de acordo com o que celebrava em seu contrato, dá impulso às pesquisas no campo da bacteriologia e também em patologia animal, além de promover cursos de bacteriologia e também no compromisso da fabricação de soros e vacinas mais usados na prática médico-veterinária (TeIXeIRA 1995).

Por conta de suas investigações na área de patologia animal, este pesquisador e seus colaboradores tiveram a oportunidade de coletar helmintos de diversos hospedeiros; estes helmintos foram identificados por Travasssos (1915) e reportados como provenientes do Instituto Pasteur de São Paulo. Porém, as referências a este material eram publicadas em trabalhos esparsos e os exemplares do acervo original nunca haviam sido listados integralmente, dentro da CHIOC, o que é feito nesta oportunidade.

\section{AGRADECIMENTO}

À Lísia Regina Guimarães, bolsista PAP, de 1996-1999, no Laboratório de Helmintos Parasitos de Vertebrados do Departamento de Helmintologia do IOC e atualmente lotada na Casa de Oswaldo Cruz, COC, Fiocruz, por participar da triagem inicial do material apresentado no presente trabalho.

\section{REFERÊNCIAS BIBLIOGRÁFICAS}

Amin, O.M. 1985. Classification, p. 27-72. In: Biology of Acanthocephala. D.W.T. Crompton \& B.B. Nickol (Eds). Cambrige, University Press, XI+519p.

Lichtenfels, J.R. \& M.H. Pritchard. 1982. A guide to the parasite collections of the world. Lawrence, American Society of Parasitologists, 79p.

Noronha, D.; A. Frisso \& F.B. Mattos. 2003. Desenvolvimento de um banco de dados para a informatização da Coleção Helmintológica do Instituto Oswaldo Cruz. Revista Brasileira de Zoologia, Curitiba, 20: 777-778.

Stepan, N. 1976. Gênese e evolução da ciência brasileira: Oswaldo Cruz e a política de investigação científica e médica. Rio de Janeiro, Artenova, 78p.

Teixeira, L.A. 1995. Ciência e saúde na terra dos bandeirantes. A trajetória do Instituto Pasteur de São Paulo, no período de 1903-1916. Fiocruz, Rio de Janeiro, 180p.

Travassos, L. 1915. Trichostrongylideos brazileiros ( $4^{\mathrm{a}}$ nota prévia). Brazil Medico, Rio de Janeiro, 29: 388-389.

. 1917. Contribuição para o conhecimento da fauna helminolojica brazileira. Revisão dos acantocefalos brazileiros. Part.1.Fam.Giganthorhynchidae Hamann, 1892. Memórias do Instituto Oswaldo Cruz, Rio de Janeiro, 9: 5-62.

Travassos, L; J.F.T. Freitas; A. Kohn. 1969. Trematódeos do Brasil. Memórias do Instituto Oswaldo Cruz, Rio de Janeiro, 67: 1- 886.

Vicente, J.J.; H.O. Rodrigues; D.C. Gomes \& R.M. Pinto. 1993. Nematóides do Brasil. Parte III. Nematóides de répteis. Revista Brasileira de Zoologia, Curitiba, 10: 19-168.

1995. Nematóides do Brasil. Parte IV. Nematóides de aves. Revista Brasileira de Zoologia, Curitiba, 12 (Supl.1): 1-273.

. 1997. Nematóides do Brasil. Parte V. Nematóides de mamíferos. Revista Brasileira de Zoologia, Curitiba 14 (Supl.1): 1-452.

Recebido em 02.III.2003; aceito em 31.V.2004. 